\title{
Acute kidney injury and posterior reversible encephalopathy syndrome in a boy with $\beta$ thalassemia major
}

\author{
Hossein Emad Momtaz ${ }^{*}$ \\ Division of Pediatric Nephrology, Besat Hospital, Hamadan University of Medical Sciences, Hamadan, Iran
}

\section{A R T I C L E IN F O}

Article Type:

Case Report

\section{Article History:}

Received: 20 June 2017

Accepted: 4 September 2017

Published online: 20 September 2017

\begin{abstract}
A B S T R A C T
Renal involvement in thalassemia major is an important concern of both pediatric nephrologists and pediatric hematologists. Both glomerular and tubular injury may precede overt kidney dysfunction in these patients and may be due to deleterious effects of hemolysis, iron overload and iron chelator therapy. Here we present a case of thalassemia major with acute kidney injury with findings in favor of hemolytic uremic syndrome and consequent posterior reversible encephalopathy syndrome who needed multiple sessions of hemodialysis and finally recovered uneventfully.
\end{abstract}

Keywords:

Acute kidney injury

$\beta$ thalassemia

Posterior reversible

Leukoencephalopathy

\section{Implication for health policy/practice/research/medical education:}

Patients with $\beta$ thalassemia major are at risk of renal damage due to multiple mechanisms. Frequent monitoring of kidney function and attention to level of iron overload, dose and duration of chelator therapy is highly recommended in this group of patients.

Please cite this paper as: Momtaz HE. Acute kidney injury and posterior reversible encephalopathy syndrome in a boy with $\beta$ thalassemia major. J Renal Inj Prev. 2018;7(3):215-217. doi: 10.15171/jrip.2018.50.

\section{Introduction}

Renal involvement in thalassemia major is an important concern of both pediatric nephrologists and pediatric hematologists. Both glomerular and tubular injury may precede overt kidney dysfunction in these patients and may be due to deleterious effects of hemolysis, iron overload and iron chelator therapy $(1,2)$.

\section{Case Presentation}

Patient is a 13-year-old boy, a case of thalassemia major who presented with chief complaint of gross hematuria since one week and epistaxis since two days before admission. He was diagnosed as thalassemia major at 6 months of age and then received pack cell transfusion every 3-4 weeks. He had history of headache, dizziness, hematemesis, pallor and tarry stool. He was on deferoxamine $1500 \mathrm{mg}$ subcutaneous 4 times weekly, deferiprone $500 \mathrm{mg} 3$ times daily and deferasirox $500 \mathrm{mg}$ twice daily. He had family history of thalassemia minor in his parents. On physical examination he was pale, pulse rate $(P R)=102 / \mathrm{min}$, respiratory rate $(R R)=25 /$ min, blood pressure $(\mathrm{BP})=120 / 70 \mathrm{~mm} \mathrm{Hg}$, temperature $=$ 36.5 axillary. Sclera was mildly icteric; heart and lung auscultation was normal. There was no organomegaly or abdominal distention but he had only mild tenderness over RUQ. In addition, he had +2 edema of lower extremities. Laboratory data was as follows: hemoglobin $=5.2 \mathrm{~g} / \mathrm{dL}$, white blood cell $(\mathrm{WBC})=4700 / \mathrm{mm}^{3}(68 \% \mathrm{PMN}, 30 \%$ lymph), platelet $=66000 / \mathrm{mm}^{3}$, mean corpuscular volume $(\mathrm{MCV})=76.9 \mathrm{fl}$, prothrombin time $(\mathrm{PT})=13$ seconds, partial thromboplastin time $(\mathrm{PTT})=30$ seconds, blood urea nitrogen $(\mathrm{BUN})=220 \mathrm{mg} / \mathrm{dL}$, creatinine $=10 \mathrm{mg} / \mathrm{dL}$, 
total bilirubin $=6.9 \mathrm{mg} / \mathrm{dL}$, direct bilirubin $=5.1 \mathrm{mg} / \mathrm{dL}$, $\mathrm{P}=7.8 \mathrm{mg} / \mathrm{dL}, \mathrm{Ca}=7.9 \mathrm{mg} / \mathrm{dL}, \mathrm{K}=5.9 \mathrm{mEq} / \mathrm{L}, \mathrm{pH}=7.24$, $\mathrm{HCO} 3=8.7 \mathrm{mmol} / \mathrm{L}$, HBsAg negative, $\mathrm{D}$-dimer = $2553 \mathrm{ng} / \mathrm{mL}$ (high), fibrinogen degradation products $(\mathrm{FDP})=20 \mathrm{\rho g} / \mathrm{mL}$ (high), fibrinogen $=3.39 \mathrm{~g} / \mathrm{L}$ (normal), C3, C4, ANA, P-ANCA, C-ANCA were all within normal range.

Peripheral blood smear showed; schistocytes and burr cells in favor of microangiopathic hemolytic anemia, G6PD assay was normal and direct coombs test was negative. Urinalysis showed; +1 blood, +1 ketone, 4-5 RBC/HPF. Renal sonography showed only bilateral enlarged kidneys with increased echogenicity.

Hemodialysis was started for him. His blood pressure was about $120-130 / 70 \mathrm{~mm} \mathrm{Hg}$ and rose slowly but never went over 150-160/90 mm Hg. Anemia persisted and he received four transfusions of packed red blood cell (RBC). With high suspicion of hemolytic uremic syndrome and also antibody mediated hemolysis, fresh frozen plasma and prednisolone were started. Renal biopsy showed evidences of tubulitis, acute interstitial nephritis, changes in arterioles in favor of microangiopathy and significant iron deposition in renal tubules and interstitium. IF study was not significant. On 11th day of admission, after apparent satisfactory recovery he developed headache, repeated vomiting, and blurred vision. Cerebrospinal fluid analysis was normal with acceptable pressure. Polymerase chain reaction (PCR) for herpes simplex virus was negative. Brain magnetic resonance imaging (MRI) showed high intensity lesions in parieto-occipital region in favor of posterior reversible encephalopathy syndrome (PRES) (Figure 1). After a day, patient developed generalized tonic colonic seizure which recurred for several episodes and finally controlled with IV sodium valproate, phenytoin and phenobarbital. On 16th day of admission serum BUN and creatinine significantly decreased and the patient was discharged after 21 days with good general condition and withholding hemodialysis. On follow up visits blood pressure was normal, thus antihypertensive

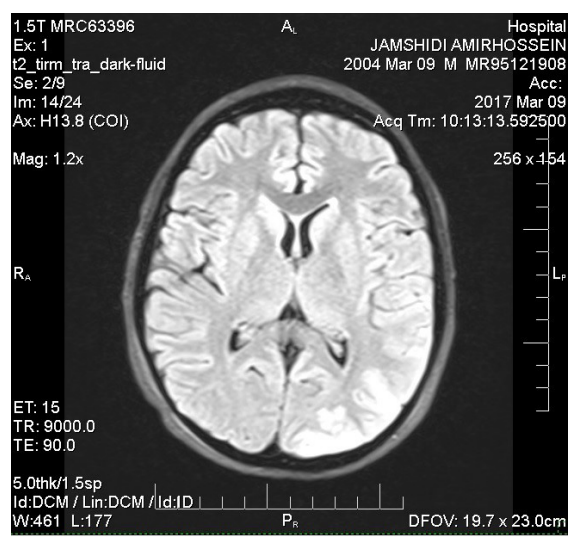

Figure 1. Brain MRI; hyperintense lesion in left parieto-occipital region in favor of posterior reversible encephalopathy syndrome (PRES). drugs were discontinued, hemoglobin remained above 10 $\mathrm{g} / \mathrm{dL}$ without pack cell transfusion, platelet count became normal and finally creatinine decreased to normal level according to age.

\section{Discussion}

Beta-thalassemia is a genetic disease caused by mutation of $\beta$ globin gene resulting in defective hemoglobin synthesis and anemia which in most severe form (thalassemia major) needs multiple, often monthly blood transfusions (1-3). Frequent RBC transfusion with subsequent iron deposition in body organs such as heart, pancreas, thyroid and liver may cause several untoward complications. Without regular blood transfusions and also proper iron chelation patients with thalassemia major may not survive even to late childhood and adolescence (4). Traditionally excess iron removal has been achieved by subcutaneous injections of deferoxamine (desferral), but newer drugs such as deferiperone and deferasirox are used frequently in recent years.

Renal involvement in thalassemia major may be due to several pathophysiologic mechanisms; renal tubular injury, iron deposition and anemia may contribute to tubular injury in thalassemia major patients.

Iron deposition in renal tubules may lead to lipid peroxidation and oxygen free radicals production causing tubular damage (5). Anemia also can cause tubular damage per se or due to causing oxidative stress in thalassemia major patients (6). Glomerular hyperfiltration is a common finding in thalassemia major patients, which can cause renal damage and decline of GFR (7). Several studies highlighted that iron chelators caused renal injury presumably due to tubular necrosis or interstitial nephritis $(8,9)$.

The main question in our case was: Is there any possible relation of thalassemia major and hemolytic-uremic syndrome (HUS)? Author found only an article which concluded that free heme from hemolysis (such as thalassemia major) can act as a trigger for atypical HUS (10). PRES is associated with hypertension in nearly $70 \%$ of cases but it may be due to in severe inflammation and endothelial injury such as sepsis, autoimmune disease, eclampsia and transplantation (11). More interestingly there are reports of PRES in patients with diagnosis of HUS $(12,13)$.

\section{Conclusion}

Our experience with this case emphasizes close monitoring of thalassemia major patients especially ones receiving multiple iron chelators for early laboratory signs of renal dysfunction, keeping in mind that hemolysis may trigger atypical HUS in patients with genetic predisposition. Posterior reversible leukoencephalopathy syndrome should be considered as a possible cause of seizure and altered level of consciousness in these patients even in absence of significant hypertension. 


\section{Author's contribution}

HEM is the single author of the paper.

\section{Conflicts of interest}

The author declared no potential conflicts of interest with respect to the case, authorship, and/or publication of this article.

\section{Funding/Support}

None.

\section{Ethical considerations}

Ethical issues (including plagiarism, data fabrication, double publication) have been completely observed by the author. Informed consent was obtained from the patient for publication.

\section{References}

1. Quinn CT, Johnson VL, Kim HY, Trachtenberg F, Vogiatzi MG, Kwiatkowski JL, et al. Thalassemia Clinical Research Network. Renal dysfunction in patients with thalassaemia. Br J Haematol. 2011; 153:111-7. doi: 10.1111/j.1365-2141.

2. Bakr A, Al-Tonbary Y, Osman G, El-Ashry R. Renal complications of beta-thalassemia major in children. Am J Blood Res. 2014 Sep 5; 4:1-6.

3. Weatherall DJ, Clegg JB. The Thalassaemia Syndromes. 4th ed. Wiley; 2008.

4. Kliegman RM, Stanton BF, St Geme JW, Schor NF, eds. Nelson Textbook of Pediatrics. 20th ed. Philadelphia, PA: Elsevier; 2016.

5. Kassab-Chekir A, Laradi S, Ferchichi S, Haj Khelil A, Feki $\mathrm{M}$, Amri F, et al. Oxidant, antioxidant status and metabolic data in patients with beta-thalassemia. Clin Chim Acta. 2003;338:79-86.

6. Nagababu E, Gulyani S, Earley CJ, Cutler RG, Mattson MP, Rifkind JM. Iron-deficiency anaemia enhances red blood cell oxidative stress. Free Radic Res. 2008;42:824-9. doi: 10.1080/10715760802459879.

7. Deveci B, Kurtoglu A, Kurtoglu E, Salim O, Toptas T. Documentation of renal glomerular and tubular impairment and glomerular hyperfiltration in multitransfused patients with beta thalassemia. Ann Hematol. 2016;95:375-81. doi: 10.1007/s00277-015-2561-2.

8. Prasannan L, Flynn JT, Levine JE. Acute renal failure following deferoxamine overdose. Pediatr Nephrol. 2003;18:283-5. doi:10.1007/s00467-002-1051-7.

9. Murphy N, Elramah M, Vats H, Zhong W, Chan MR. A case report of deferasirox-induced kidney injury and Fanconi syndrome. WMJ. 2013;112:177-80.

10. Frimat M Tabarin F, Dimitrov JD, Poitou C, HalbwachsMecarelli L, Fremeaux-Bacchi V, et al. Complement activation by heme as a secondary hit for atypical hemolytic uremic syndrome. Blood. 2013;122:282-92. doi: 10.1182/ blood-2013-03-489245

11. Hobson EV,Craven I, Blank SC. Posterior reversible encephalopathy syndrome: a truly treatable neurologic illness. Perit Dial Int. 2012;32:590-4. doi: 10.3747/ pdi.2012.00152

12. Li-ping Y, Bo Y, Ming G, Qin Z, Ling L, Bo H. Reversible posterior leukoencephalopathy syndrome in a child with hemolytic uremic syndrome. J Clin Hypertens (Greenwich). 2014;16:538-9. doi: 10.1111/jch.12337

13. Agarwal R, Davis C, Altinok D, Serajee FJ. Posterior reversible encephalopathy and cerebral vasoconstriction in a patient with hemolytic uremic syndrome. Pediatr Neurol. 2014;50:518-21. doi: 10.1016/j.pediatrneurol.2014.01.024.

Copyright (c) 2018 The Author(s); Published by Nickan Research Institute. This is an open-access article distributed under the terms of the Creative Commons Attribution License (http://creativecommons.org/licenses/by/4.0), which permits unrestricted use, distribution, and reproduction in any medium, provided the original work is properly cited. 